\title{
Mudanças de contexto e negociações de identidades em sala de aula
}

\author{
Context changes and identity negotiations in classroom
}

Alinne Santana Ferreira - Instituto Federal de Brasília - linne.one@gmail.com

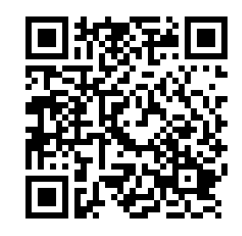

Resumo: O presente artigo defende que os estilos de fala adotados pelos interagentes são construídos no contexto, levando-os a projetarem ou a negociarem identidades no curso da interação. Pretende-se demonstrar os resultados de uma investigação etnográfica no contexto de sala de aula em uma instituição de Ensino Superior. O objetivo do trabalho é revelar como as identidades são negociadas por meio do estilo de fala e como os interagentes sinalizam pistas de contextualização, que os enquadram no contexto situacional. Este estudo se situa-se no quadro da Sociolinguística Interacional e incorpora contribuições das noções de contexto defendidas por Duranti \& Goodwin, assim como das concepções cognitivistas defendidas por van Dijk. Ademais, pretende-se revelar como o contexto em curso determinará a escolha de um estilo de fala mais formal ou menos formal pelos professores colaboradores e como as identidades dos professores e dos alunos são negociadas no momento da interação. Para realizar este estudo, foram feitas microanálises etnográficas por meio de filmagens de aulas com observação participante, totalizando corpus de, aproximadamente, duas horas de aulas gravadas. Como resultados desta pesquisa, pode-se indicar que a ideia de uma identidade fixa não constitui mais uma realidade no mundo pós-moderno. Por essa razão, as identidades fluidas e líquidas, defendidas por Giddens e Bauman, aplicam-se ao contexto desta pesquisa, uma vez que o contexto em curso determinará as negociações ou as invocações/projeções de identidades pelos professores colaboradores.

Palavras-chave: estilo de fala, contexto, identidade, ensino superior.

\begin{abstract}
This paper advocates that speech styles adopted by interactors are constructed in context, leading them to project or negotiate identities in the course of interaction. It aims to demonstrate the results of an ethnographic research in the classroom context at a higher education institution. The objective of this work is reveal how identities are negotiated through the speech style and how the interactors indicate contextualization clues, which sets them in the situational context. This study states itself in interactional sociolinguistics framework and incorporates contributions from the notion of context advocated by Duranti \& Goodwin, as well as the cognitive conception defended by van Dijk. Furthermore, it is intended to reveal how current context determines the choice for a more or less formal speech style by collaborating teachers and how teachers and students' identities are negotiated at the interaction moment. To conduct this study, ethnographic microanalyses were made by filming classes with participant observation, constituting a corpus of approximately two hours of recorded classes. As results of this research, we can affirm that the idea of a fixed identity is not a reality in the postmodern world. For this reason, fluid and liquid identities, advocated by Giddens) and Bauman, can be applied in this research context, because current context will determine negotiations or invocations/ projection of identities by collaborating teachers.
\end{abstract}

Keywords: speech style, context, identity, higher education. 


\section{INTRODUÇÃO}

Neste trabalho serão discutidos os conceitos de contexto, de discurso, de identidade e de estilo de fala, por meio da análise dos dados gerados na interação em sala de aula.

Os estudos interacionais delineados por Goffman ([1964] 2002) concebem que a linguagem, além de ser de natureza social, precisa ser estudada dentro das práticas sociais numa determinada cultura. É o que esse autor chama de situações sociais, que dizem respeito ao contexto nos quais os atos de fala ocorrem. Por isso, o trabalho com a Sociolinguística Interacional objetiva revelar como os interagentes negociam e partilham significados sociais durante as trocas verbais. Isso requer uma prática de pesquisa voltada para a interpretação dos significados sociais, e não mais para a categorização dos níveis de linguagem de grupos sociais.

Este trabalho faz parte de uma pesquisa etnográfica realizada em salas de aula do Ensino Superior, em uma instituição de ensino particular, e objetiva demonstrar como professores e alunos negociam as identidades por meio do estilo de fala adotado. Para isso, faz-se necessária uma análise dos diversos contextos que foram delineados nas interações gravadas e transcritas, as quais fazem parte do corpus total desta microanálise etnográfica.

\section{Questões Metodológicas}

Os dados foram gerados por meio de gravações de áudio de encontros realizados com as duas professoras pesquisadas e com as duas turmas do curso de Pedagogia, além de anotações de campo, que corresponderam à fase inicial da pesquisa de mestrado. Por se tratar de uma pesquisapiloto realizada em momento no qual o projeto de pesquisa ainda estava passando por aprovação no Comitê de ética da Universidade de Brasília', optou-se por gravar somente o áudio para preservar a imagem das colaboradoras de pesquisa, cujos nomes também não foram divulgados.

Partiu-se do paradigma da etnografia por ela oferecer aos pesquisadores uma importante contribuição para análise dos dados por ser sensível à cultura, ao contexto e à construção conjunta da atividade educacional. (MERCER, 1998, p.118)

Para Schwandt (2006, p.196-197), a compreensão interpretativa pressupõe a reflexividade, ou seja, os enunciados não são apenas algo, eles fazem algo, pois compõem atos de fala que devem ser interpretados pelos pesquisadores. Além disso, a compreensão interpretativa

\footnotetext{
1 A decisão de trabalhar com imagens exige do pesquisador preocupação maior com questões referentes à ética da pesquisa. Por isso, foi preciso que, antes de iniciar as gravações de imagens no campo, a pesquisadora submetesse o projeto de pesquisa ao Comitê de Ética da Universidade de Brasília. Toda a documentação foi enviada e avaliada pelo Colegiado, sendo aprovada com base na resolução 196/96, do CNS/MS, que regulamenta a ética da pesquisa com seres humanos.
}

compreende a indexicalidade, que corresponde à interpretação de palavras ou enunciados no contexto de sua utilização. Para isso, é necessário que o pesquisador esteja sensível para observar aspectos não somente linguísticos como questões gramaticais e de prosódia - mas também os paralinguísticos, a exemplo da cinésica, da proxêmica e de todos os sinais não-verbais.

Por esse motivo, optou-se pela pesquisa etnográfica, pois as práticas sociais do dia a dia não estão ao alcance da pesquisa variacionista de tradição positivista, pois ela se preocupa apenas em organizar um determinado grupo social em categorias (COUPLAND, 2007). Por isso, é necessário afirmar que a veracidade e a exatidão dos dados de pesquisa, como na abordagem quantitativa, não constituem condições necessárias para alcançar as interpretações dos significados sociais, pois alcançam somente um contexto generalizado e, por vezes, estanque. A análise qualitativa, por sua vez, procura, de modo minucioso, estudar o contexto situacional, acompanhando suas mudanças e a relação disso com a construção dos significados partilhados pelos interagentes.

Por conseguinte, a pesquisa qualitativa situa-se nas experiências vividas, com foco nos significados das ações sociais. Isso significa que essa pesquisa não pretende estudar formas linguísticas idealizadas, haja vista que se compromete a estudar a língua em uso.

\section{ESTILO DE FALA}

Coupland (2007, p.25) afirma que o estilo cria significados sociais nos quais os falantes criam uma imagem de si. Isso leva à reflexão de que não existe um único estilo, mas estilos que são construídos pelos atores sociais a partir dos significados sociais inseridos no contexto de sala de aula. Um professor, ao iniciar uma aula, já possui uma ideia, mesmo que não seja externada por ele, do que seja ser professor, e isso irá determinar algumas de suas posturas que projetam uma imagem dele para os alunos. Porém, o que foi observado é que, na primeira interação gravada, a professora $A^{2}$ traz uma imagem de si que irá contribuir para negociação do estilo de fala adotado por ela e pela aluna 1, que condiz com uma situação formal de orientação de projeto de pesquisa. Mas em alguns momentos o estilo formal da professora A é substituído por um mais simétrico, ao negociar com a aluna 2 uma outra data para a entrega do trabalho.

2 Adotam-se aqui as letras A e B para referência às duas professoras do curso de Pedagogia que colaboraram com esta pesquisa. Por questões de organização, os alunos colaboradores serão enumerados em A1, A2, $\mathrm{A} 3, \mathrm{~A} 4 \ldots$ e em As, quando vários alunos falam juntos a mesma coisa num único turno de fala. 


\section{Excerto 013(Aula 01):}

05 A1: Vai ter que reformular isso (...) aí eu vou poder falar sobre as dificuldades de leitura (...) no $5^{\circ}$

06. ano?

07 Professora A: (...) no $2^{\circ}$ ano que não são alfabetizados pra saber se esses métodos são utilizados

08 com o primeiro e segundo ano isso... Ou se são utilizados um, ou se são dois, ou se são três, ou se

09 há uma maior variedade de métodos, ou a situação-problema está certa e seu título tá fora, né, ou

10 então o contrário... Inclusive no objetivo geral, olha, partiu mais da sua situação-problema (ela lê

11 o objetivo muito rapidamente) aqui você colocou particular, a turma. Aqui no referencial teórico

12 se você for manter (...) sobre os métodos, no seu referencial teórico você vai ter que abordar isso,

13 tá? Os métodos alfabéticos, silábico, fônico.

14 Professora A: Diga com as suas palavras o que é que você quer fazer, independente do (...)

15 o que você quer saber? (...) E aí?

16 A1: Conhecer, estudar sobre as dificuldades que os alunos têm, por exemplo, no $5^{\circ}$ e $6^{\circ}$ ano ou até

17 mesmo do $1^{\circ}$ em diante quando eles aprendem a ler, eles, eu mesmo tenho dificuldade quanto à

18 leitura; eu leio, leio, leio e não consigo, então é a dificuldade que a criança tem, que o adolescente

19 tem em estudar e não compreender, de não decodificar; ele decorou as palavras, ele vê, olha tudo,

20 mas não consegue compreender, transparecer, repassar pro papel. Então o tipo de dificuldade,

21 porque se você lê algo e não consegue fazer um resumo, então é uma dificuldade, né, de leitura.

Nesse momento, a professora assume o seu papel institucional, que a faz adotar um estilo de fala mais formal e uma proxêmica de maior distanciamento da aluna. Nota-se isso durante toda a interação da professora A com a aluna ${ }^{1}$. Nos momentos em que a professora lia na tela do notebook a produção da aluna, esta se aproximava daquela, mas no momento em que a professora começava a falar, explicando o que deveria ser modificado no trabalho, a aluna voltava o corpo para longe da professora numa atitude de escuta, abaixando a cabeça quase sempre e anotando os pontos a serem melhorados em seu trabalho. Na linha 14 a professora usa o verbo dizer no modo imperativo, demostrando atitude profissional ao tentar entender o que a aluna escreveu e buscar caminhos para orientá-la a aprimorar o projeto de pesquisa.

\section{Excerto 02 (Aula 01):}

12 A2: Posso mandar por e-mail?

13 Professora A: Trouxe o relatório? Nem o relatório, nem o fichamento?

14 A2: Não, não tinha como imprimir.

15 Professora A: Você trouxe o projeto?

16 A2: Eu trouxe até onde eu fiz... E o meu projeto eu já troquei de tema... Já tô editando pela

17 terceira vez, porque eu achei muito amplo.

18 Professora A: O relatório?

19 A2: Não, o projeto... Eu posso mandar por e-mail? (...)

20 Professora A: E o projeto de pesquisa você manda pro meu e-mail que eu vou te dar um .

21 feedback, um retorno... Me manda do jeito que ele tá, porque se for esperar ele ficar...

22 A2: Perfeito, então eu vou mandar o que eu já tinha feito.

23 Professora A: O que você já conseguiu escrever dele manda pro meu e-mail. (...)

3 As transcrições deste trabalho seguem as indicações de Gumperz (1982a e 1982b) e Marcuschi (2007). 
Irvine (2001, p.24) afirma que o estilo de fala envolve os falantes como agentes no espaço social e sociolinguístico, ao negociar as suas posições e objetivos dentro de um sistema de distinções e possibilidades, sendo os atos de fala construídos ideologicamente. Lefebvre (2001, p.206) defende que o estilo escolhido pelos falantes de uma comunidade linguística é para que eles se apropriem de uma determinada situação. O autor acrescenta que a escolha de um estilo em lugar de outro revela que o falante já possui uma grande quantidade de informação sobre si mesmo, a situação em que se encontra, o efeito que quer produzir sobre os interagentes e a relação que quer manter com eles (LEFEBVRE, 2001, p. 234).

Fica bem claro que a professora alternou o estilo formal que estava utilizando com a aluna 1 para um estilo um pouco menos formal ao interagir com a aluna 2. O que se pôde perceber é que a professora não saiu de seu papel social, mas as suas representações sociais a respeito de como agir com um aluno que não entregou o trabalho em dia a fez assumir uma identidade mais flexível, o que a fez solicitar que a aluna enviasse o trabalho por meio de correio eletrônico.

Nas interações ocorridas em situações de aula, os estilos de fala do professor e do aluno sinalizam os papéis sociais realizados por eles e delimitam simetrias e assimetrias na interação em curso.

Portanto, a grande preocupação da análise de estilo é tentar entender o contexto (ou os contextos) e observar como os autores sociais partilham significados (COUPLAND, 2007).

\section{Noções de Contexto: Questões Cognitivas E Questões SOCIAIS}

Para compreender o contexto à luz das teorias que serão aqui discutidas, faz-se necessário reconhecer que ele só é definido no curso da interação (GUMPERZ, 1982a).

Van Dijk (1977) demonstra a importância das teorias a respeito da Pragmática para uma análise contextual. A pragmática estuda como a língua é usada pelas pessoas para seus próprios propósitos e com as suas próprias limitações e concessões 41(MEY, 2001, p.207) determinadas pelos significados culturalmente construídos. Por isso, a natureza cognitiva dos atos pragmáticos precisa ser levada em conta na interpretação das interações humanas, pois é socialmente que um falante exibe os atos internos por meio dos atos de fala (VAN DIJK, 1977, p.212). Para esse autor, os interagentes possuem

$4 \mathrm{Mey}$, J. L.: Pragmatics Acts. In: Pragmatics: an introduction. Malden, Massachustts: Blackwell, 2001. (Tradução Nossa) informações prévias que os fazem reagir de forma agressiva ou amigável. Por exemplo, se alguém der uma tapa forte nas costas, talvez conhecer ou não conhecer essa pessoa leve o interagente a escolher uma forma de reagir. Portanto, é o conhecimento prévio (background) que o falante possui que dará a ele informações sobre como reagir numa situação dessas.

As informações vêm de vários canais, como, por exemplo, propriedades da estrutura do enunciado (base gramatical); recursos paralinguísticos (velocidade, stress, prosódia, altura da voz, gestos, expressões faciais, movimentos corporais); contexto de observação; conhecimentos e crenças do interagente; conhecimento a respeito de qual tipo de interação está acontecendo, baseado no que aconteceu antes do contexto da interação; conhecimentos e crenças derivados de atos de fala anteriores; semântica geral e outros tipos de conhecimento geral de mundo (frames). (VAN DIJK, 1977).

Conforme van Dijk (1977), é necessária a construção de esquemas mentais (frames) para a construção da noção de contexto. "Um dos princípios metodológicos que se devem ter em mente é que a noção de contexto é uma abordagem teórica e uma abstração cognitiva" ${ }^{5}$ (VAN DIJK, 1977, p.217). Fica claro que a posição de van Dijk acerca de contexto é muito mais interna/cognitivista do que externa/sociointeracionista. Segundo ele, a compreensão de um ato de fala se dá antes de se produzir um enunciado, e o contexto é processado mentalmente para depois se manifestar socialmente.

As contribuições desse autor são bastante produtivas para a compreensão dos esquemas mentais (pressupostos) que levam a um enquadramento do interagente ao contexto em que a interação acontece, mas é preciso retomar a concepção mais social de contexto apresentada por Gumperz ${ }^{6}$ (1982a) por meio da noção das Pistas de Contextualização.

5 Van Dijk. T. Context and cognition: Knowlwdge Frames and Speech compression. In: Journal of Pragmatics 1, 1977, 211-232. (Tradução Nossa)

6 Gumperz (1982, p. 152) afirma que é na estrutura da superfície das mensagens que os falantes sinalizam e os ouvintes interpretam a atividade que está ocorrendo. Essas sinalizações são chamadas pistas de contextualização e devem ser estudadas relacionadas ao contexto, e não de forma abstrata. 
A análise linguística, nessa concepção, precisa ser contextualizada, pois os interagentes dão pistas, a todo instante, que devem ser interpretadas pelo pesquisador. Gumperz (2002, p. 08) defende o conceito de pistas de contextualização como sendo pistas linguísticas, verbalizadas ou não,que levam os falantes a negociarem significações durante a interação. As pistas de contextualização são concebidas com os seguintes pressupostos: (a) uma interpretação sempre dependerá do contexto em que os atos de fala ocorrem; e (b) os pressupostos contextuais moldam a interpretação dos interagentes.

As ideias de Gumprez (1982a; 2002) e de van Dijk (1977) complementam-se quando o primeiro afirma que são as inferências conversacionais feitas pelos interagentes que geram compreensão sobre as trocas verbais. Porém, é necessário sinalizar que van Dijk entende que as pressuposições são muito mais realizadas por questões cognitivas do que por questões sociais/externas.

Ademais, a noção de contexto no campo de estudo da Sociolinguística Interacional precisa ser vista como algo fluido, dinâmico e que se atualiza a cada instante na interação face a face - o que pôde ser notado nos dados gerados que compõem o corpus deste trabalho.

Seria possível a existência de vários contextos num único ambiente de interação? Sim. Os dados gerados demonstram que o contexto realmente se atualiza no decorrer da interação, a exemplo da interação da professora com os alunos do curso de Pedagogia durante a apresentação de trabalho da disciplina Literatura Infantil (excerto 03). Quando se pensa em apresentação de trabalho, logo se infere uma situação em que os interagentes adotarão o estilo de fala

\section{Excerto 03 (Aula 02):}

formal na maioria do tempo.

Todavia, na interação gravada, as alunas optaram por uma apresentação mais informal, modificando a estrutura tradicional da sala e transformando-a em um ambiente de chá de poesia com mesas de quatro cadeiras dispostas pela sala.

No início, duas alunas começam a dialogar, como se estivessem na mesa de uma cafeteria conversando sobre duas autoras de poemas infantis, mas logo se nota que se trata de uma encenação e que, na verdade, as alunas se apoiavam em papéis para não esquecerem as falas, o que deu a esse primeiro momento da apresentação um estilo mais formal, devido à preocupação em traçar a biografia das duas autoras.

Depois desse momento, segue-se uma apresentação dos poemas das autoras com outras alunas vestidas a caráter e fazendo um tipo de encenação. Percebeu-se que toda a apresentação do trabalho foi feita dessa maneira, sendo que, ao final, as alunas do grupo de trabalho pedem para que as outras colegas da turma possam recitar outros poemas das autoras entregando a elas papéis com os poemas.

Após toda apresentação, entra a professora B e avalia positivamente a apresentação do grupo. Depois disso, as alunas entregam uma mensagem sobre o que é ser professor para que ela leia. Infere-se que a entrega dessa mensagem ocorreu por se tratar do último encontro da disciplina. Ao ler a mensagem, a professora começa a chorar, a agradecer e a elogiar o grupo e a turma, além de utilizar estratégias de esquiva quando elogiada pela aluna 5 (linha 49).

44 Professora B: eu recebi uma mensagem que o grupo pediu que a gente partilhasse, tá...então

45 vamos lá... "ser professor... Ser professor é muito mais do que transmitir o conhecimento; é

46 aquele que ensina com dedicação e com paciência; é aquele que quebra os nossos galhos;

47 aquele que, quando tudo está difícil, ele abre o sorriso e diz: calma você vai conseguir; é agir

48 com simplicidade, com companheirismo e estar sempre disposto a te ajudar a qualquer hora;

49 enfim todas essas características se resumem em você; não é à toa que podemos afirmar que...

50 você é a nossa professora. ((professora se emociona e dá pista de que irá chorar)).

51 As: [Ah...

52 Desejamos a você um Feliz Natal e um ano repleto de realizações. Foi um imenso prazer tê-la

53 como nossa querida e estimada professora". ((ainda chorando))

54 A4: com certeza.

55 ((Palmas))

56 ((professora abraça os componentes do grupo))

57 A5 - Olha só, professora, nós sabemos que a mensagem dela serve pra todos nós também...

58 você é uma verdadeira educadora.

59 Professora B: Obrigada, gente, eu sei que a gente tem falhas, mas eu tento dar o melhor pra

60 vocês... e a gente tem uma multiplicidade de semestres, né, gente? Obrigada por tudo. 
É a situação que delineará o contexto e os atos de fala dos interagentes. Portanto, a identificação do contexto e as mudanças que ocorrem ao longo da interação são de fundamental importância para compreender como os participantes interagem e como negociam posições. No contexto em questão, tudo levaria à afirmação de que a formalidade prevaleceria em grande parte da aula. Todavia, a metodologia escolhida pelo grupo de alunas para apresentar o trabalho e a resposta da professora a respeito disso criou um clima de grande informalidade e simetria entre professora e alunas.

Goodwin e Duranti (1992) afirmam ser a fala a criadora do contexto, mas que também o comportamento não-verbal pode criar. Além disso, o contexto envolve a perspectiva dos interagentes. Os autores também apresentam a diferença entre cenário (espaço social) e contexto: o primeiro diz respeito ao quadro social e espacial e o segundo às ações, escolhas linguísticas, movimentos cinésicos que o interagente escolhe para dar pistas, fazendo com que os outros façam inferências e possam se enquadrar na situação interativa.

Ao se compreender língua como ação social, passa-se a perceber que, por contexto, não se deve entender somente um cenário. É claro que alguns papéis sociais são executados em determinadas instituições, mas apenas o contexto em curso poderá sinalizar aos interagentes como irão se comportar e quais escolhas linguísticas e paralinguísticas irão fazer.

$\mathrm{Na}$ interação gravada entre a professora A e algumas alunas do curso de Pedagogia, a constante atualização dos contextos e a forma natural e rápida com que os interagentes se enquadravam a eles demonstram a constante atualização do contexto em um único ambiente: a sala de aula.

\section{Excerto 04 (Aula 01):}

36 A1: Quais são essas técnicas aí, professora? Os métodos que a gente vai usar? Através de

37 questionário ou formulário...

38 Professora A: Técnicas de coleta, é como você materializar, vai usar questionário... Você

39 vai usar formulário.

40 (...)

41 F1: Tá tudo errado?

42 A1: Tá tudo errado.

43 Professora A: Não, não tá tudo errado.

44 A1: Só a metade.

Na aula gravada (excerto 04), a aluna 1 trouxe os dois filhos à faculdade, e eles sempre ficavam circulando pela sala de aula. Inclusive, em alguns momentos, ela pedia que eles sentassem ou que fizessem silêncio no momento em que estava sendo orientada pela professora A. Isso comprova que um mesmo cenário comporta diversos contextos, os quais se atualizam sempre e que podem ocorrer, simultaneamente, num mesmo espaço social.

Na linha 38, o filho 1 da aluna 1 pergunta se estava tudo errado no trabalho da mãe/aluna, talvez por ter acompanhado a professora corrigindo e pedindo para melhorar diversos pontos durante a orientação.

Antes da pergunta da criança, estava ocorrendo uma orientação de projeto de pesquisa e as identidades de professora e de aluna estavam bem evidentes, por ambas optarem por um estilo de fala mais formal. Quando a criança se aproxima e faz a pergunta à mãe, que também é aluna, nota-se, pelo tom de voz mais infantilizado, que tanto a aluna 1, como a professora A, dirigem-se à criança e se enquadram àquela nova situação, a um novo contexto que modificou o curso da interação, tornando-a mais informal, naquele momento, fazendo com que transpareça na aluna 1 a identidade de mãe.

No excerto 02, fica marcada também uma mudança de contexto quando a aluna 02 entra na sala de aula com o intuito de negociar um novo prazo para a entrega do trabalho e se dirige-se à professora que, naquele momento, se encontrava lendo a minuta do projeto da aluna 01 . Ao perceber a presença da aluna 2, a professora A muda o estilo de fala, sendo que a atenção da professora e de todos os presentes em sala volta-se para a aluna 02 .

Desse modo, o contexto precisa ser analisado, conforme pontuam Goodwin e Duranti (1992), como um delineador da cultura e da organização social de um grupo, sendo um processo dinâmico e intrinsecamente atualizado. 


\section{AS NEGOCIAÇÕES DE IDENTIDADE EM SALA DE AULA: PROFESSOR EXIGENTE, COMPETENTE OU FLEXÍVEL?}

Pensar sobre identidade é pensar numa complexidade de selfs que acompanham o professor e o aluno. Consoante Castells (1999, p.23), toda identidade é constituída pela soma do eu e dos outros. Por identidade, entende-se a fonte de significado e experiência de um povo e constituem fontes de significados para os próprios atores, pois é construída por eles em um processo de individualização.

Woodward (2000) afirma que a subjetividade envolve a compreensão que se tem do eu (self), envolvendo as emoções conscientes e inconscientes do que se é. Envolve os pensamentos e sentimentos mais pessoais do sujeito e as posições que ele assume e externa, por se considerar identificado com elas e que constituirão as suas identidades.

De Fina (2007) apresenta a noção de que a identidade se manifesta no discurso e na participação nas práticas sociais, tanto individualmente como coletivamente. Os interagentes constroem identidades que os projetam como um tipo específico de pessoa ou projetam identidades coletivas quando falam ou agem como parte de um grupo ou de uma instituição à qual pertencem. Coupland (2007) também afirma a existência de uma projeção que torna determinado interagente parte de determinado grupo social. Para esse autor, a identidade é uma meta da ação social. (COUPLAND, 2007, p. 108).

Cabe observar a diferença entre papel social e identidade estabelecida por Castells (1999). Para ele, ser mãe, fumante e membro de alguma igreja, ao mesmo tempo, diz respeito aos papéis que são definidos por normas estruturadas pelas instituições e organizações da sociedade. A importância desses papéis para influenciar as ações de pessoas depende de negociações entre os sujeitos e as instituições de que fazem parte. As identidades, portanto, só serão geradas por meio do processo de individualização e de negociação com o meio social no qual os sujeitos interagem.
Ter o papel social de professoras universitárias não será ingrediente necessário para que as colaboradoras de pesquisa projetem imagem de si como profissionais exigentes ou competentes a todo momento. Assim também ocorre com os alunos do curso de Pedagogia: nem sempre o papel social de aluno fará com que eles ajam sempre do mesmo jeito (Conferir excerto 04).

Para isso, é preciso observar como Hall (2006) define a identidade no período de pós-modernidade. Para ele, essa é a era das identidades fragmentadas, da crise constante das identidades, pelo fato de as mudanças estruturais e institucionais terem levado as identidades fixas a um colapso, tornando-as provisórias, variáveis e problemáticas. Trata-se, então, de uma era da pluralização das identidades.

Além disso, muitas teorias na área da educação estabeleceram uma compreensão de relacionamento entre professores e alunos com muito mais simetria, mesmo que as instituições educacionais exijam que o professor tenha um alto arsenal teórico e que cumpra com as ementas das suas disciplinas.

Bauman (2005, p. 17) chama de era líquido-moderna este momento no qual as identidades são fluidas e negociáveis, sendo projetadas apenas quando os interagentes precisam demonstrar pertencimento.

Tornamo-nos conscientes de que o 'pertencimento' e a 'identidade' não têm a solidez de uma rocha, não são garantidos para toda a vida, são bastante negociáveis e revogáveis, e de que as decisões que o próprio indivíduo toma, os caminhos que percorre, a maneira como age e a determinação de se manter firme a tudo isso - são fatores cruciais tanto para o pertencimento quanto para a identidade. (BAUMAN, 2005, p.17)

O conflito identitário entre o professor competente e o professor exigente foi observado no discurso das duas professoras. Em contextos formais, as identidades de professor exigente e competente ficam mais claras.

\section{Excerto 05 (Aula 01):}

01 Professora A: Aí você pode fazer o seguinte, você reestrutura o mais rápido que você puder

02 e manda pro meu e mail... (a professora lê o projeto em silêncio) Aqui também na metodologia

03 tem que deixar bem claro qual vai ser a escola que você vai fazer essa coleta, com que

04 instrumento você vai fazer no local de pesquisa, se você vai fazer com uma turma de $1^{\circ}$ ano ou se

05 vai fazer só com um grupo de alunos ou se vai fazer em várias turmas de $1^{\circ}$ ano, ainda que

06 depois você pode mudar a escola, mas como uma previsão. 


\section{Excerto 06 (Aula 02):}

41 Professora B: Mais algum? Vou pedir pra fazer um comentário aqui, como vocês estavam com

42 medo dos outros trabalhos que foram apresentados, do estilo dessas duas autoras, bem

43 diferenciado, passarem. Por poesia as meninas estavam preocupadas, "professora, como que nós

44 vamos fazer? A gente não tem como representar". Sei que foram surgindo ideias, no grupo foram

45 surgindo ideias, que eu achei bastante interessantes, esse trabalho foi bastante rico e trabalhar com

46 poesias a gente pode perceber que até o clima e o espaço foi preparado pra isso, isso é de extrema

47 importância, elas ficaram preocupadas por ver ao longo dos trabalhos, com a qualidade que foi

48 feita, criatividade.

Nos dois excertos, o estilo de fala adotado pelas professoras A e B evidenciam uma maior escolha pela formalidade, no momento em que tratam de assuntos mais relacionados a aspectos teóricos que norteavam a aula. Toda vez que elas assumiam esse discurso, a postura corporal ficava mais ereta, e elas se distanciavam mais dos alunos, tanto no olhar, quanto na proxêmica. Isso demonstra que a identidade do professor exigente afina-se com o status que ele deve ter em sala de aula. Em meios acadêmicos, é preciso demonstrar conhecimento e, para isso, o professor precisa ser um avaliador constante do desempenho dos alunos, conforme se observa no discurso das duas professoras. Além de o discurso revelar identidade de professor exigente, as professoras também projetam identidade de professor competente.

Do mesmo modo, as professoras optavam por se aproximar mais dos alunos, adotando um estilo mais informal de fala, principalmente a professora $B$, que projetou, na maioria da aula, uma relação simétrica, projetando a ideia da professora que abraça os alunos e emociona-se com a mensagem que o grupo entregou a ela.
Além de a professora B projetar uma identidade de profissional flexível, ao optar por demonstrar sentimentos aos alunos e ao se aproximar deles com abraços, tirando fotos e conversando informalmente depois de um lanche ser servido, ficou claro que os alunos compartilham dessa identidade quando a aluna 5 diz à professora B que ela era uma verdadeira educadora. Os alunos identificam-se com a professora (excerto 03, linha 48), pois a mensagem que a emocionou servia para todos eles. Esse compartilhar de identidades é bem comum em cursos de formação de professores, principalmente no de Pedagogia, que possui um público muito grande que já exerce a profissão.

Ao contrário da professora B, a professora A projeta, na maioria das vezes, a identidade do professor exigente. Nos dados gerados, os únicos momentos em que essa professora alterna o estilo de fala para uma maior informalidade, olhando mais diretamente para as alunas, é quando há alguma necessidade de negociar datas e suporte para o envio de trabalhos.

\section{Excerto 07 (Aula 01):}

62 Professora A: Você vai mandar o projeto pro meu e-mail, viu?

63 A1: Depois eu te mostro aqui o que eu (o que fiz o projeto).

64 Professora A: Dá uma lida primeiro pra você ter certeza de que é isso, tá? Tem muito

65 material sobre isso. O relatório é definitivo.

66 A1: O relatório não, o outro (....) É, gasta tinta demais pra depois pra...

67 Professora A: É, mas se tiver notebook dá pra ler aqui em sala.

68 A3: É melhor, né?

69 Professora A: Não precisa tá imprimindo. Tem meu e-mail?

70 Professora A: No próximo sábado... É na próxima aula não é a avaliação ainda, então se

71 você me mandar essa semana eu ainda leio e sábado a gente senta de novo. 
Coupland (2007), para contextualizar o estudo da identidade, apresenta cinco processos que envolvem as ações humanas em contextos sociais: alvo, enquadre, expressão, chave e carregamento ${ }^{7}$.

Alvo: refere-se à projeção ou ao alvo a que se destinam os atos de identidade (um falante e um ouvinte).

Enquadre: o valor da identificação e impacto dos objetivos linguísticos depende de qual enquadre discursivo está em jogo.

Expressão: diz respeito a como um falante se representa e quais vozes podem ser assumidas em seu discurso.

Chave: termo emprestado de Dell Hymes que corresponde às pistas que os interagentes dão para que os outros possam inferir sua(s) identidade(s).

Carregamento: é o momento em que os interagentes negociam suas identidades.

Todos esses cinco processos foram notados nas interações gravadas. As professoras e os alunos faziam, a todo instante, inferências conversacionais baseadas em seus conhecimentos socioculturais sobre o que é ser professor e o que é ser aluno, e projetavam aos outros uma autoimagem que achavam propícia para aquele contexto, sendo que os interagentes enquadravam-se com facilidade no contexto negociado.

As duas professoras escolhem um discurso específico, com um estilo de fala com mais ou menos formalidade, utilizando-se também de sinais não-verbais como pistas para que os alunos identificassem a identidade assumida naquele momento e para que eles também pudessem se enquadrar na interação.

Do mesmo modo, os alunos que apresentaram o trabalho, na aula 02, optaram por preparar um ambiente menos formal, com uma metodologia de trabalho mais prática e menos teórica, pois a identidade negociada entre eles e a professora $B$ era de um trabalho elaborado de modo criativo, conforme o discurso da professora $B$, no excerto 06.

Portanto, percebe-se, claramente, que, assim como assegura Bauman (2005), estamos na era líquidomoderna, na qual as identidades são tão fluidas que é difícil estabelecer rótulos únicos que confiram ao professor uma única identidade. Ao contrário disso, os professores transitam em contínuos dinâmicos, nos quais não há extremos. Afirma-se, assim, que estamos na era das identidades fragmentadas (HALL, 2006). E isso se reflete diretamente na sala de aula. O ser professor, em alguns momentos, é negociado com o ser aluno.

Conforme Giddens (1991, p. 37-38), a modernidade introduz um dinamismo elementar nas coisas humanas e rompe o referencial protetor da pequena comunidade e da tradição, substituindo-as por instituições muito maiores e impessoais. Para ele, a autoidentidade torna-se problemática na modernidade, pois questões existenciais e ontológicas vão passando por uma crise. Por isso, autodefinir-se é tão complicado nos dias modernos, por ser esta uma era da fragmentação de identidades, da desintegração de tudo e de todos: do sujeito, do discurso, dos fenômenos e da realidade (GIDDENS, 1991, p.150).

\section{Considerações Finals}

A partir dos dados gerados e analisados neste trabalho, é visível que o contexto passa a ter uma significação muito mais abrangente, a qual não deixa de envolver concepções cognitivistas, pois os interagentes fazem o processamento das informações a partir de seus conhecimentos de mundo. Porém, a noção de contexto estende-se muito mais quando se admite a noção social das interações.

Percebeu-se, assim, que o conceito de contexto adotado na perspectiva desta pesquisa abrange as práticas sociais realizadas em sala de aula, e que este cenário não pode determinar uma única perspectiva. Pelo contrário, o contexto é atualizado a cada instante e o partilhar de significados é negociado por todos os envolvidos na interação, sendo modificados ou reestruturados a partir do interesse dos interagentes.

Sendo assim, as interações numa sala de aula de ensino superior não pressupõem apenas um contexto de estilo formal, que será sempre o escolhido pelos interagentes. No contexto desta pesquisa, os estilos de fala adotados pelas duas professoras e pelos alunos condizem com a identidade que cada interagente necessita projetar num determinado contexto. E essas identidades são determinadas pelas diversas crenças que cada um possui e por questões sociais e culturais internalizadas por eles, fazendo-os negociar diferentes identidades em diferentes contextos.

Entender o que é estilo de fala e por que há, durante a aula, alternâncias constantes de estilo, que ora se apresenta mais formal, com marcas de assimetria, ora menos formal, com marcas de simetria, foi de grande importância para chegar a algumas descobertas, pois, de acordo com esta pesquisa, estilos de fala relacionam-se com identidades negociadas e projetadas. Essa afirmação pode ser explicada quando Coupland (2007, p.61), discutindo algumas considerações de Allan Bell, afirma que a variação de estilo expressa a identificação do falante com o grupo. Se o professor permite a negociação de identidades em sala de aula, o seu estilo tenderá a ser mais informal. Mas se o momento da aula é teórico, o professor tenderá a invocar/projetar identidades relacionadas a um estilo de fala mais formal.

7 Termos originais: targeting, framing, voicing, keying e loading dentro da significação de cada um neste contexto. (tradução nossa) 
A língua não pode ser concebida de um ponto de vista estritamente formal. Os aspectos socioculturais precisam ser levados em conta, incluindo a Pragmática, Análise de Discurso, Sociologia, Antropologia, Psicologia Social e muitas outras áreas que ampliam a análise sociolinguística por se preocuparem em desvendar e em discutir a negociação dos significados sociais por meio da interação face a face.

\section{Referências}

BAUMAN, Z. Identidade: entrevista a Benedetto Vecchi. Rio de Janeiro: Jorge Zahar, 2005. Trad. Carlos Alberto Medeiros.

CASTELLS, M. O Poder da Identidade. São Paulo: Paz e Terra, 1999. Tradução: Klauss Brandini.

COUPLAND, N. Style: language variation and identity. New York: Cambridge University Press, 2007.

DE FINA, A. Style and stylization in the construction of identities in a card-playing club. In: AUER, Peter. Style and social Identities: alternative approaches to linguistic heterogeneity. Berlin: GmbH \& Co, 2007.

DIJK. T. V. Context and cognition: knowledge and speech act comprehension. Journal of Pragmatics 1, 1977, 211-232.

DURANTI, A \& GOODWIN C. Rethinking Context: an introduction. In: DURANTI, A \& GOODWIN C. Rethinking context. New York: Cambridge University Press, 1992.

GIDDENS, A. As consequências da modernidade. Trad. Raul Fiker. São Paulo: Editora da UNESP, 1991.

GOFFMAN, E. A Situação Negligenciada. Trad. Pedro M. Garcez. In: RIBEIRO, B \& GARCEZ, P (orgs.). Sociolinguística Interacional. São Paulo: Loyola, 2002.

GUMPERZ, J. Discourse strategies. Cambridge: Cambridge University Press, 1982a. . Language and social identity. Cambridge:

Cambridge University Press, 1982b.
. Convenções de contextualização (1982). Trad. MEURER, José Luiz \& Heberle, Viviane. In: RIBEIRO, B \& GARCEZ, P (orgs.). Sociolinguística interacional. São Paulo: Loyola, 2002.

HALL, S. A identidade cultural na pós-modernidade. Rio de Janeiro: DP\&A, 2006. Trad. Tomás Tadeu da Silva \& Guaracira Lopes Louro.

IRVINE, J. "Style" as distinctiveness: the culture and ideology of linguistic differenciation. In: ECKERT, P. \& RICKFORD, J. R. Style and sociolinguistic variation. United Kingdom: Cambridge University Press, 2007.

LEFEBVRE, C. As Noções de Estilo. In: BAGNO, M. Norma linguística. São Paulo: Edições Loyola. p. 203-36, 2001.

MERCER, N. As perspectivas socioculturais e o estudo do discurso em sala de aula. In: COLL, C \& EDWARDS, D (orgs.). Ensino, aprendizagem e discurso em sala de aula: aproximações do estudo do discurso educacional. Porto Alegre: Artmed, 1998.

MEY, J. L. Pragmatics Acts. In: MEY, J. L. Pragmatics: an introduction. Malden, Massachustts: Blackwell, 2001.

SCHWANDT, T. A. Três posturas epistemológicas para a investigação qualitativa. In: NORMAM, K. O planejamento da pesquisa qualitativa. Porto Alegre: Artmed, 2006.

WOODWARD, K. Identidade e diferença: uma introdução teórica e cultural. In: SILVA, T. T. Identidade e diferença: a perspectiva dos estudos culturais. Petrópolis, RJ: Vozes, 2000.

Recebido: em 21/05/2014

Aceito em: 19/11/2014 